\title{
The Supply of Telecommunication and Electronic Services via Interfaces and Portals
}

\author{
Anna Franziska Mehnert
}

\begin{abstract}
From 1 January 2015 the place of supply of telecommunication, broadcasting and electronic services will be where the customer is located. This means, with regard to $\mathrm{B} 2 \mathrm{C}$ supplies, that the supplier has to determine the applicable VAT rate of the country where the customer is located and is liable to pay the tax due to the tax authorities of that Member State. The Implementing Regulation 1042/2013 introduces Article 9a which deals with electronic and telephone services provided through the internet and supplied via an intermediary. In such a case it is not only important to determine with certainty where the customer is located in order to find out the applicable tax rate, but also, in a supply chain with one or more intermediaries, who the supplier of the service is and thus liable to pay the VAT. This is complicated by the fact that not every taxable person in the supply chain is also considered to be taking part in the supply.
\end{abstract}

\section{Introduction}

On 1st of January 2015 a change in legislation of the EU VAT system will amend the place of supply rules with regard to B2C supplies of services of telecommunication operators, broadcasters and other electronic service providers established within the EU. The new rules shift the place of supply from the country where the supplier is located to the country where the consumer is located as is already applicable for eservice providers established outside the EU. With the new place of supply rules the EU responds to the existing distortion of competition between EU and non-EU service providers and creates a level playing field between them. The new rules are the result of the 'VAT Package' adopted in 2008 intended to bring the treatment of electronic services in line with one of the main principles of VAT, namely that consumption taxes are effectively charged where consumption actually takes place, 
which is also in line with the OECD principles on the taxation of ecommerce.

Under the new B2C place of supply rules for telecommunication, broadcasting and electronic services, as there is no reverse charge mechanism for B2C supplies, the foreign supplier, when providing services to a final consumer, is liable to pay VAT to the tax authorities. Thus, it is important to define with certainty who the supplier is. However, telecommunication and electronic services are often supplied via digital intermediaries such as internet platforms, mobile operators, portals or marketplaces for mobile applications. If the service is directly supplied to the end consumer, for example, when a consumer purchases and downloads music directly from an artist's own website, it can be said with certainty that the artist is the supplier of the service to the customer and the one who has to pay the VAT due to the tax authorities.

However, the recent emergence of the digital market and especially the quickly developing mobile communication business with new technologies constantly creating new devices, contents and services such as smart phones, app stores and other internet based platforms and portals have led to an extension of digital supply chains. Digital services are increasingly provided via intermediaries where there is no direct supply between the content owner and the customer. Digital supply chains often involve many different participants such as content providers, content aggregators, platform and portal providers and payment aggregators to name but a few. Electronic and telecommunication services are usually provided through several of these digital intermediaries which all enter into different types of contracts which each other (e.g. agency or commissionaire agreements, licensing agreements, etc.). This causes problems as to determine with certainty who in the supply chain the supplier of those services is for VAT purposes. If, for example, a developer of a mobile application enters into an agreement with an app store over which he is going to sell his app, the question arises, who is the supplier to the final customer (and thus liable to pay the VAT in the country of the nontaxable person) - the content owner of the app (the developer) or the app store? In those cases it is not always entirely clear who in the supply chain is the supplier of the service for VAT purposes.

The Implementing Regulation $1042 / 2013^{1}$ introduces the new Article 9a, which deals with electronic and telephone services provided through the internet and supplied by one or more intermediaries such as a telecommunications network, interface or portal. Article 9a determines

1 Regulation (EC) 1042/2013, 7 October 2013, [2013] O] L 284/1 
which member of the digital supply chain qualifies as the supplier for VAT purposes and will have to issue the VAT invoice to the private consumer. This provision is based on the commissionaire agreement laid down in Article 28 of the 'VAT Directive'. ${ }^{2}$ The article includes the presumption that each party in the supply chain purchases and supplies the service to the next party in the chain. This presumption may be rebutted by any taxable person in the supply chain, subject to the condition that this is explicitly reflected in the contractual arrangements between two taxable persons (e.g. the content owner and the intermediary, whereby the intermediary must explicitly indicate the content owner as the supplier).

Article 9a only covers telecommunication and electronic services while broadcasting services are excluded from its scope and thus excluded from the scope of this article. A definition of 'telecommunication services' is already provided in Article 24 (2) of the VAT Directive which remains valid as of 2015. The non-exhaustive list of examples in Article $6 a$ (1) of the Implementing Regulation further clarifies which services are included in the definition. Telecommunication services include fixed and mobile telephone and videophone services, telephone services provided through the internet, voice mail and other call management services and access to the internet. Electronically supplied services and broadcasting services are not covered by telecommunication services within the meaning of Article 24 (2). 'Electronic services' are defined in Article 7 of the Implementing Regulation 282/2011 ${ }^{3}$ and comprise "services which are delivered over the internet or an electronic network and the nature of which renders their supply essentially automated and involving minimal human intervention [...]." The amended paragraph 3 of Article 7 explicitly excludes from electronically supplied services the online purchase of tickets to cultural, artistic, sporting, scientific, educational, entertainment or similar events. Moreover is the online booking of hotels and restaurants, as well as the online hiring of cars excluded from the scope of electronic services. Broadcasting and telecommunication services are not covered by the concept of electronically supplied services' for the purpose of the VAT Directive.

This article will provide an answer to the question how to determine the supplier of electronic services for the purpose of the new B2C place of supply rules, where this service is supplied through the internet and supplied via several digital intermediaries. To this end, the article will elaborate on the functioning of Article $9 a$ of the Implementing Regulation 1042/2013.

2 Directive 2006/112/EC, 28 November 2006, [2006] O] L 347/1

3 Regulation (EC) 282/2011, 15 March 2011, [2011] O] L 77/1 


\section{The New Place of Supply Rules for Telecommunications, Broadcasting and Electronic Services 2015}

\subsection{Current rules}

Under the current VAT rules for telecommunications, broadcasting and electronic services supplied within the EU, the place of supply for B2B services is the EU country where the customer belongs, i.e. where they have their main business or fixed premises, their permanent address or usually lives, whereas for B2C services it is the EU country where the supplier belongs, i.e. where he is registered, has his permanent address or usually lives. This means, that an EU business, when supplying a business established in another EU country, must not charge VAT as the customer must account for VAT under the reverse charge mechanism according to Article 44 of the VAT Directive. When an EU business supplies a consumer in the EU, on the basis of Article 45 of the VAT Directive, VAT is to be charged in the country where the business is established, irrespective of where the customer belongs.

For supplies of telecommunications, broadcasting and electronic services from and into the EU the current rules allocate the place of supply where the customer belongs (where the customer has their main place of business or fixed premises, permanent address or where they usually reside). This means in practice, under Articles 44 and 59 of the VAT Directive, that an EU business supplying services to a business or consumer established outside the EU will usually not charge EU VAT (under reverse of Article 59a VAT Directive EU Member States may levy VAT if the service is effectively used and enjoyed in that Member State for the prevention of double or non-taxation). A business established outside the EU and supplying services to a business within the EU, does not charge VAT as the customer must account for VAT under the reverse charge mechanism (Article 44 VAT Directive). If a non-EU business supplies telecommunications or broadcasting services to a consumer in the EU, VAT is to be charged in the EU country where the service is effectively used and enjoyed (Article 59b VAT Directive). If the non-EU business supplies electronic services to a consumer in the EU, VAT must be charged in the country where that consumer belongs (Article 58 VAT Directive). 
Figure 1. Place of supply under the current rules

\begin{tabular}{|l|l|l|l|}
\hline B2B & Outbound EU & Inbound EU & Within the EU \\
\hline $\begin{array}{l}\text { Place of supply is } \\
\text { outside the EU - } \\
\text { usually no EU VAT } \\
\text { charged }\end{array}$ & $\begin{array}{l}\text { EU country where the } \\
\text { customer belongs (reverse } \\
\text { charge mechanism) }\end{array}$ & $\begin{array}{l}\text { EU country where } \\
\text { the customer } \\
\text { belongs (reverse- } \\
\text { charge } \\
\text { mechanism) }\end{array}$ \\
\hline B2C & $\begin{array}{l}\text { Place of supply is } \\
\text { outside the EU - } \\
\text { usually no EU VAT } \\
\text { charged } \\
\text { (might be subject to } \\
\text { 'use and enjoyment' } \\
\text { override) }\end{array}$ & $\begin{array}{l}\text { Telecoms/broadcasting: } \\
\text { EU country where the service } \\
\text { is effectively used and enjoyed }\end{array}$ & $\begin{array}{l}\text { EU country where } \\
\text { the supplier } \\
\text { belongs }\end{array}$ \\
\hline
\end{tabular}

\subsection{New rules from 1 January 2015}

From 1 January 2015 the place of supply rules for telecommunications, broadcasting and electronic services will change and will be taxed in the country where the customer belongs irrespective of whether the customer is a business or consumer and whether the supplier is based inside or outside the EU. For businesses (taxable persons) that means the country where the business is registered or has fixed premises receiving the service and for individual consumers (non-taxable persons) it is the country where they are registered, have a permanent address or usually reside. ${ }^{5}$ This means that if an EU business supplies to another EU business no VAT is charged and the customer must account for VAT under the reverse charge mechanism. If the EU business supplies a consumer living in another EU country, VAT must be charged in the EU country where the consumer belongs and not where the business is established. For supplies to businesses or consumers outside the EU, no EU VAT is charged but if the service is effectively used and enjoyed in an EU country, that country may levy VAT.

With regard to supplies of non-EU businesses to businesses based in the EU, the customer must account for VAT under the reverse charge mechanism, while supplies to a consumer in the EU are taxed in the EU country where the consumer belongs.

4 If the service is effectively used and enjoyed in an EU country, that country can decide to levy VAT.

5 European Commission (Taxation and Customs Union) http://ec.europa.eu/taxation customs/taxation/vat/how vat works/tele com/index en.htm 
Since under the new rules of B2C telecommunications, broadcasting and electronic services the place of supply is where consumption actually takes place, namely where the end user is located, the supplier technically has to take into account 28 different VAT rates ranging from 15 to 27 per cent when supplying services within the EU. In order to facilitate the new rules the optional one-time registration scheme, the so-called mini one-stop shop (MOSS) will be extended to EU providers of electronic services from 2015. The MOSS will be a simplification measure that allows the supplier to register, declare and pay the VAT due on supplies of electronic services to final consumers in other Member States via a web portal in his own Member State. He will therefore submit, once a quarter, a single VAT declaration to his home administration and can thus avoid registering for VAT in each Member State in which he has a customer. ${ }^{6,7}$

Figure 2. Place of supply under the new rules

\begin{tabular}{|c|c|c|c|}
\hline & Outbound EU & Inbound EU & Within the EU \\
\hline B2B & $\begin{array}{l}\text { Place of supply is } \\
\text { outside the EU - } \\
\text { usually no EU VAT } \\
\text { charged }\end{array}$ & $\begin{array}{c}\text { EU country where the customer } \\
\text { belongs (reverse-charge } \\
\text { mechanism) }\end{array}$ & $\begin{array}{l}\text { EU country } \\
\text { where the } \\
\text { customer } \\
\text { belongs } \\
\text { (reverse charge } \\
\text { mechanism) }\end{array}$ \\
\hline B2C & $\begin{array}{l}\text { Place of supply is } \\
\text { outside the EU - } \\
\text { usually no EU VAT } \\
\text { charged } \\
\text { (might be subject } \\
\text { to 'use and } \\
\text { enjoyment' } \\
\text { override) } 8\end{array}$ & $\begin{array}{c}\text { Telecoms/broadcasting/electronic } \\
\text { services: } \\
\text { EU country where the customer } \\
\text { belongs }\end{array}$ & $\begin{array}{l}\text { EU country } \\
\text { where the } \\
\text { customer } \\
\text { belongs }\end{array}$ \\
\hline
\end{tabular}

6 S. Claessens and I. Lejeune; 'Taxation of B2C TBE Services under EU VAT from 2015'. International VAT Monitor, January/February 2014, p. 9

7 Expert Group on taxation of the digital economy, Working Paper on VAT issues, 9. January 2014

8 If the service is effectively used and enjoyed in an EU country, that country can decide to levy VAT. 


\section{Supply of Telecommunications and Electronic Services via Intermediaries under the New Article 9a}

Where telecommunication and electronic services are supplied to a final consumer (B2C) after the $1^{\text {st }}$ of January 2015, the supplier is responsible for paying the VAT to the tax authorities. For this reason, it is essential to determine who the supplier of these services is, especially when they are not directly supplied to the final consumer but via several intermediaries. With the emergence of the digital market, it is very common that telecommunication and electronic services are supplied via digital intermediaries such as app stores, platforms and portals which replace the traditional buyer-seller model.

For VAT purposes, these intermediaries can take the form of a commissionaire or an agent. The commissionaire acts in his own name but on behalf of another person, whereas the agent acts in the name of and on behalf of another person. Under a commissionaire agreement, the commissionaire is treated as the one receiving the service from the principal and supplying it further to the final customer. ${ }^{9}$ For example, when a developer of a mobile phone application sells his app via an app store, from which the customers can purchase the app by paying to the app store and afterwards download it to their mobile phones, the app store acts as a commissionaire and subsequently sells the goods to the private consumer. The commissionaire does not take legal title to the content provided but from a VAT perspective, the commissionaire acts as though he was the owner and the supply will be treated as two fictitious supplies provided consecutively. ${ }^{10}$ Thus, every time a private consumer downloads an app from the app store there are effectively two sales (the content owner selling to the app store and the app store selling to the final customer). The commissionaire will then be treated as the supplier and has to issue invoices in his own name. In these cases, there is a contract directly between the commissionaire and the end consumer.

A pure agent, on the contrary, acts in the name and for the account of the principal and is not deemed to be the supplier nor recipient of the service (he is providing the service intermediary to the principal). The supply of the service thus takes place directly between the principal,

9 Article 28 Directive 2006/112/EC, 28 November 2006, [2006] O] L 347/1 ('VAT Directive')

10 Case C-464/10 Henfling and Others [2011] ECR I-0000 
who is the supplier, and the final customer. The agent only supplies his service to the principal who is responsible for the collection of VAT on the sales to the private customer in accordance with the normal place of supply rules of the VAT Directive. ${ }^{11}$

Figure 3. Intermediary acting as an agent and not taking part in the supply

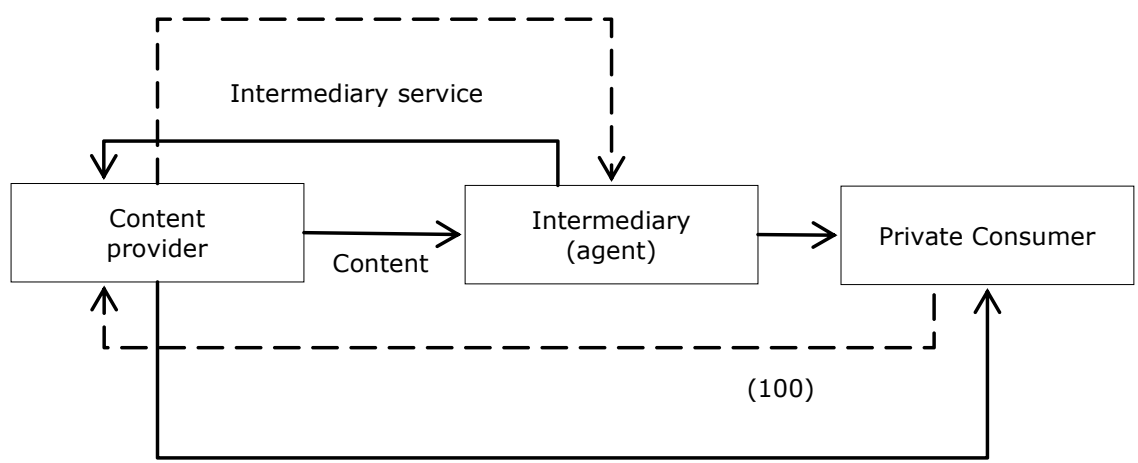

Invoice for service supplied

$\longrightarrow$ Supply of service

Normally, intermediaries are only regarded as taking part in the supply if they fulfill the conditions of Article 28 of the VAT Directive which reflects the situation of a commissionaire agreement. According to the provision of Article 28, a taxable person is deemed to be the supplier if that person (1) takes part in a supply of services, (2) acts in his own name but (3) on behalf of another person. ${ }^{12}$ If the intermediary (in the above mentioned example the app store) does not act as a commissionaire, i.e. he does not fulfil the requirements of Article 28 of the VAT Directive, the app developer is the supplier of the service and has to issue a VAT invoice every time his app is downloaded from the app store. Whether an intermediary is acting as an agent or

11 Article 46 Directive 2006/112/EC, 28 November 2006, [2006] O] L 347/1 ('VAT Directive')

12 Article 28 Directive 2006/112/EC, 28 November 2006, [2006] O] L 347/1 ('VAT Directive') 
commissionaire the contractual relations between the parties and the facts are decisive. However, the contractual arrangements must also be reflected in the economic reality. In case of doubt, the economic reality principle prevails. ${ }^{13}$

Article $9 a$ is based on the commissionaire arrangement of Article 28 of the VAT Directive. ${ }^{14}$ The Article includes the presumption that an intermediary generally acts as a commissionaire, i.e. in his own name but on behalf of the electronic service provider. The intermediary is therefore deemed to have received and further supplied the electronic or telecommunication service himself. In the above mentioned example, under Article 9a, the app store is regarded as the supplier and the one liable to pay the VAT to the tax authorities. Article 9a thus serves as a simplification mechanism in order to define with certainty who the supplier is for VAT purposes; in that way it provides legal certainty for the parties involved in the supply and ensures the collection of the tax. ${ }^{15}$. Article $9 a$ is constructed in such a way that the presumption will apply unless it is rebutted by a taxable person taking part in the supply. ${ }^{16}$

\subsection{How does Article 9a work?}

Article 9a presumes that each intermediary in the supply chain between the e-service provider and the end consumer is deemed to have received and supplied the service himself. Thus, if the intermediary is an app store from which customers can download apps to their mobile phones, and fulfills the conditions laid down in Article 28, this app store operator is to be regarded as the e-service provider and the one responsible to charge the VAT and not the content owner of the app who sells his app via the app store.

However, the presumption of Article 9a can be rebutted by a taxable person in the supply chain. For the rebuttal, two conditions must be met: (1) the service provider is explicitly indicated as the supplier and, (2) this is reflected in the contractual arrangements between the

13 Case C-464/10 Henfling and Others [2011] ECR I-0000

14 S. Claessens and I. Lejeune; 'Taxation of B2C TBE Services under EU VAT from 2015'. Int'I VAT Monitor, January/February 2014, p. 9

15 Explanatory notes on the EU VAT changes to the place of supply of telecommunications, broadcasting and electronic services that enter into force in 2015, European Commission, published 3 April 2014, p. 20

16 Ibid., p. 22 
parties. ${ }^{17}$ The first condition involves that the service provider must be explicitly indicated as the supplier by the intermediary who rebuts the presumption. The invoices issued by each taxable person taking part in the supply and the invoice or receipt to the final costumer must clearly identify the electronic service in question and the supplier thereof. Moreover, this must be reflected in the contractual arrangements between the parties. ${ }^{18}$ If the conditions for rebuttal are fulfilled, the commissionaire structure is not presumed and the intermediary acts as an agent which is not affected by the rule of Article 9a.

Figure 4 illustrates the situation under the presumption of Article 9a (1). The intermediary is deemed to receive the service and supply it further to the final consumer as if he would be the service provider. The intermediary acts as a commissionaire.

In figure 5 the intermediary rebutted the presumption and acts as an agent. This means that the content owner of the app is the service provider who makes the supply to the final consumer. He will also be the one determining the place of supply and paying the VAT due on the supply. As required under Article $9 a$ (1) this must be explicitly mentioned on the receipt or bill to the final consumer as well as on the invoices between the intermediary and the content owner. Moreover, the contractual arrangements must clearly reflect the situation.

The presumption cannot be rebutted if a taxable person is authorizing the charge to the customer, authorizing the delivery of the service or setting the general terms and conditions of the supply. If only one of these functions is carried out by a taxable person, he cannot rebut the presumption of Article 9 and will be caught by the commissionaire structure. $^{19}$

17 Ibid., p. 24/25

18 Ibid., p. $22 / 23$

19 Ibid., p. 34 
Figure 4. Intermediary caught by the presumption of Article 9a

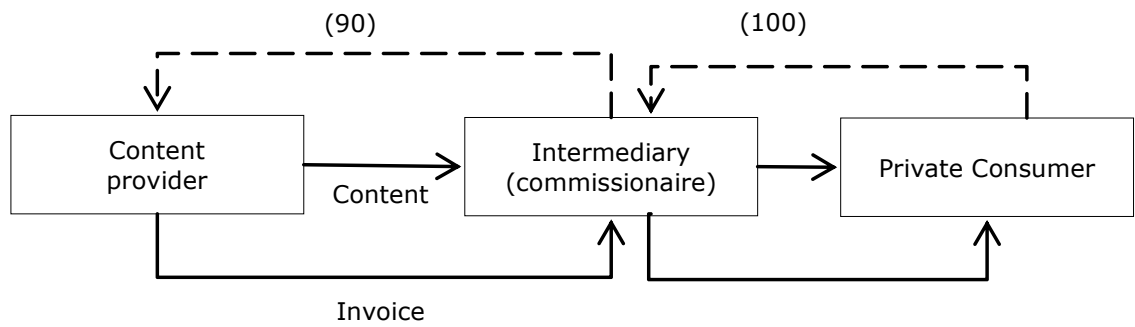

$\underset{-\rightarrow}{\longrightarrow} \begin{aligned} & \text { Supply of service from a VAT perspective } \\ & \text { Cash flow }\end{aligned}$

Figure 5 . Rebuttal of the presumption by the intermediary

(10)

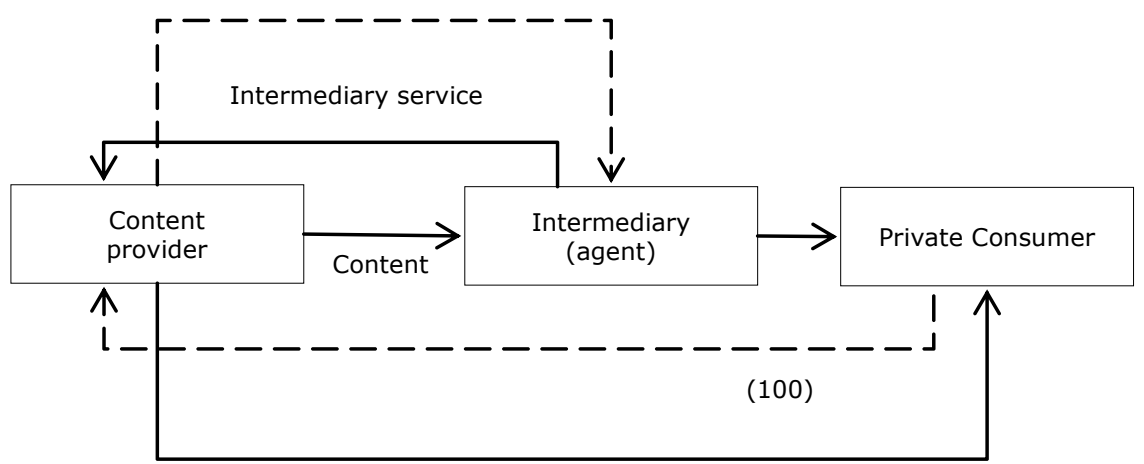

Invoice for service supplied

$\longrightarrow \quad \begin{aligned} & \text { Supply of service } \\ & \text { Cash flow }\end{aligned}$ 


\subsection{Multiple intermediaries in the supply chain}

As mentioned before, there can be several intermediaries in the supply chain. The conditions for the rebuttal apply to each and every intermediary taking part in the supply. If, in a supply chain with multiple intermediaries, one of the intermediaries did not rebut the presumption by identifying the e-service provider as the supplier, he must be regarded as the supplier by the intermediaries following further down the supply chain. If the following intermediaries want to rebut the presumption, it is not possible anymore for them to indicate the original service provider as the supplier and can only go back to the first intermediary caught by the presumption. ${ }^{20}$ The reason for this has to do with the purpose of Article 9a, to tax as closely as possible to the final consumer. Therefore, in order to correctly analyse the status of each intermediary, one has to start at the final consumer's level and move upstream in the supply chain. ${ }^{21}$ Only if the conditions for a rebuttal of the presumption are met by all intermediaries in the supply chain, the e-service provider will remain the supplier to the end consumer and will be responsible for determining the applicable VAT rate (the place of supply of the consumer) and paying the VAT due.Figure 6 illustrates the rebuttal of one intermediary in a supply chain with several intermediaries. The first intermediary is caught by the presumption of Article 9a (1) and is deemed to receive the service from the content owner and further supply it. The first intermediary in the supply chain is thus to be regarded as the supplier of the service. The second intermediary rebuts the presumption, subject to the conditions for rebuttal, and is consequently not regarded as the supplier by the third intermediary. Intermediary number 3 has to go back to the first intermediary caught by the presumption in order to identify the supplier. If the third intermediary does not rebut the presumption to be the supplier himself, he will be regarded the supplier of the service to the final consumer.

20 Ibid., p. 24

21 Ibid., p. 35 
Figure 6 . Rebuttal of the presumption by one intermediary in the supply chain

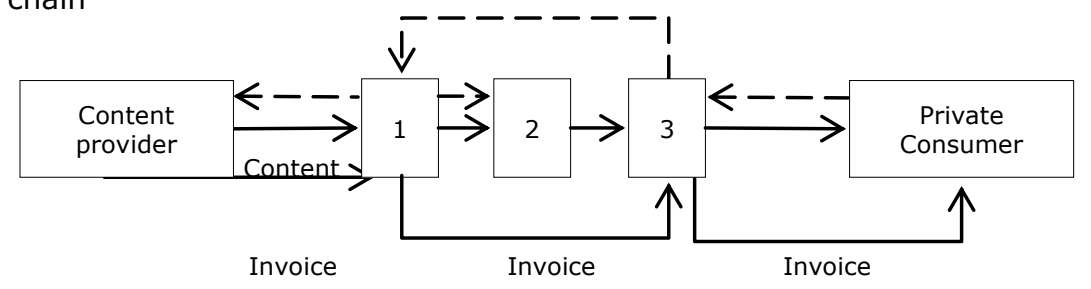

$\longrightarrow \begin{aligned} & \text { Supply of service from a VAT perspective } \\ & \text { Cash flow }\end{aligned}$

\subsection{Who takes part in the supply?}

There is an exception to the presumption of the commissionaire structure under Article 9a for taxable persons merely facilitating the delivery of content or the payment such as mobile operators or credit card companies. ${ }^{22}$ In order for the presumption of Article 9a (1) to be applicable the taxable person must take part in the supply. This is not always easy to assess if the services are provided through an app store or telecommunications network. Thus, the facts and the contractual and legal relations need to be taken into account; however, there is a substance over form approach with regard to the assessment. If the situation is not clearly enough stipulated in the contractual situation, the facts of the transaction will be an important indicator. It must be reflected in the economic reality whether a taxable person is taking part in the supply or not. Thus, a contractual clause excluding a taxable person from taking part in the supply must be reflected in the economic reality otherwise it is not sufficiently defined. ${ }^{23}$

If a taxable person only processes payments or facilitates the delivery of the content, for example businesses providing payment services or an internet provider through which the content is delivered, that person cannot be regarded as taking part in the supply only on account of these functions. However, if that person also fulfills other functions in the supply chain it can of course be regarded as taking part in the supply. The Explanatory Notes of the Commission provide a list of examples which can, however, not be decisive on their own. Thus, a

22 Article 9a (3) Regulation (EC) 1042/2013, 7 October 2013, [2013] OJ L 284/1

23 Explanatory Notes, p. 28 
taxable person presumably takes part in the supply if that person, for instance, owns or manages the platform over which the services are delivered, provides customer service and is in possession of customer data. If this person has influence or control over the pricing and on how the product is marketed in the virtual market place, such as an app store or a website, which puts this person in a significantly more prominent position in the supply than others, and if this person is the one who issues the VAT invoice or receipt to the final consumer and has legal obligations and liabilities towards the supply of the service, this would be indicative as to whether that person might be part of the supply. ${ }^{24}$ In any case, all the facts and features of the supply have to be taken into account in order to determine with certainty who takes part in the supply and who does not.

In this chart the Internet provider is not taking part in the actual supply because he is merely facilitating the content and cash flow. If the Internet provider is not further involved in the supply other than providing internet via wi-fi or cable over which the supply is carried out, his function is not sufficient to be considered taking part in the supply. The processing of payments and the carrying of the content is thus not enough to be seen as taking part in the supply. The same rules are applicable to mobile operators. If a mobile operator only provides the network through which the e-service is delivered to the customer's phone, he cannot be regarded as taking part in the supply. However, if the participation of a mobile operator exceeds the mere processing of payment or carrying of content he must be considered as taking part in the supply. In order to assess whether this is the case it should be tested if the network is essential to the supply and if the collecting of the payment includes additional elements such as the use if certain premium services. ${ }^{25}$

24 Ibid.

25 Ibid., p. 28 
Figure 7. Internet provider processing payments is not part of the supply chain

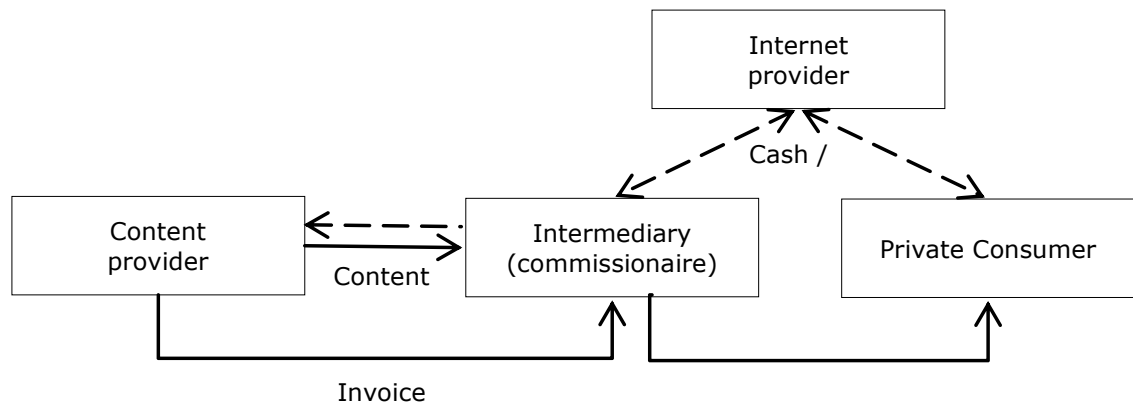

$\longrightarrow \begin{aligned} & \text { Supply of service from a VAT perspective } \\ & \text { Cash flow }\end{aligned}$

\section{Conclusion}

The new VAT B2C place of supply rules for telecommunications, broadcasting and electronic services shift the place of supply from the country where the supplier is located to the place where the customer is located. Since there is no reverse charge mechanism applicable to B2C supplies, it is the supplier of these services who is responsible to pay the VAT to the tax authorities. With regard to the supply of telecommunication and electronic services it is common that these services are provided through intermediaries such as app stores or telecom operators. Digital supply chains can be very long involving multiple intermediaries which gives rise to the question who in the supply chain is the supplier to the final customer and liable to pay the VAT to the tax authorities. The fact that the members of a supply chain enter into all kinds of different agreements with each other, for example licensing, agent or commissionaire agreements, the latter two having different VAT implications, makes it difficult to determine with certainty who the supplier to the final customer is and consequently difficult to establish who should charge local VAT to the customer. This article intended to answer the question how to determine the supplier if the service is provided through the internet and supplied by several intermediaries. Under the new Article 9a of the Implementing Regulation 1042/2013 each intermediary between the electronic service 
provider and the final consumer is presumed to be the supplier unless this presumption is rebutted. In a supply chain with several intermediaries it is the one supplying to the final customer who is to be treated as the supplier of the service and the one who has to issue the VAT invoice. The presumption of Article 9a can help the parties participating in a supply chain providing electronic or internet telephone services, to define the supplier providing these services to the nontaxable final consumer and responsible to charge VAT applicable in the Member State where the customer belongs. However, much depends on the contractual relations between the parties involved.

If an intermediary identifies the original service provider as the supplier, which must be explicitly stated in the contractual arrangements, he is not caught by the presumption anymore to be the supplier himself. If, in a supply chain with several intermediaries, one intermediary does not rebut the presumption, the subsequent intermediaries have to regard him as the supplier. If the supply chain involves several parties which are not to be considered as taking part in the supply as their activities are subordinate, for example the processing of payments, Article 9a is not applicable. Here a factual and contractual analysis on a case by case basis is necessary, whereby the economic reality prevails, whether a person takes part in the supply or not. 